\title{
Protein-protein interactions among signaling pathways may become new therapeutic targets in liver cancer (Review)
}

\author{
XIAO ZHANG $^{1 *}$, YULAN WANG $^{1 *}$, JIAYI WANG $^{1,2}$ and FENYONG SUN ${ }^{1}$ \\ ${ }^{1}$ Department of Clinical Laboratory Medicine, Shanghai Tenth People's Hospital of Tongji University, \\ Shanghai 200072; ${ }^{2}$ Translation Medicine of High Institute, Tongji University, Shanghai 200092, P.R. China
}

Received May 29, 2015; Accepted July 6, 2015

DOI: $10.3892 /$ or.2015.4464

\begin{abstract}
Numerous signaling pathways have been shown to be dysregulated in liver cancer. In addition, some protein-protein interactions are prerequisite for the uncontrolled activation or inhibition of these signaling pathways. For instance, in the PI3K/AKT signaling pathway, protein AKT binds with a number of proteins such as mTOR, FOXO1 and MDM2 to play an oncogenic role in liver cancer. The aim of the present review was to focus on a series of important protein-protein interactions that can serve as potential therapeutic targets in liver cancer among certain important pro-carcinogenic signaling pathways. The strategies of how to investigate and analyze the protein-protein interactions are also included in this review. A survey of these protein interactions may provide alternative therapeutic targets in liver cancer.
\end{abstract}

\section{Contents}

1. Introduction

2. PI3K/AKT signaling pathway

3. PPIs between PI3K/AKT and other signaling pathways

4. Proteins that physically interact with AKT as its downstream effectors in liver cancer

5. AKT-involved PPIs revealed in other models

6. Therapies targeting PI3K/AKT-involved PPIs

7. PPIs in other signaling pathways

8. How to investigate and analyze PPIs

9. Conclusion

Correspondence to: Dr Jiayi Wang or Dr Fenyong Sun, Department of Clinical Laboratory Medicine, Shanghai Tenth People's Hospital of Tongji University, No. 301 Middle Yanchang Road, Shanghai 200072, P.R. China

E-mail: karajan2@163.com

E-mail: sunfenyongtongji@126.com

*Contributed equally

Key words: signal transduction, PI3K/AKT signaling, therapy, apoptosis, hepatocellular carcinoma, PPI investigation

\section{Introduction}

Liver cancer is the sixth most common cancer and the second most common cause of cancer-associated mortality worldwide (1). Approximately $75 \%$ of all primary liver cancer types are hepatocellular carcinoma (HCC) that formed from liver cells. Liver cancer can be formed from other structures in the liver such as bile duct, blood vessels and immune cells. Secondary liver cancer is a result of metastasis of cancer from other body sites into the liver. The major cause of primary liver cancer is viral infection with either hepatitis $\mathrm{C}$ virus (HCV) or hepatitis B virus (HBV), which leads to massive inflammation, fibrosis and eventual cirrhosis in the liver. Many genetic and epigenetic alterations have been identified in hepatocytes during HCV and HBV infection (2). Other causes, such as alcohol, aflatoxin, high-grade dysplastic nodules, obesity, diabetes and smoking may increase the risk of liver cancer. Surgical resection is an option for liver cancer treatment (3), whereas liver transplantation can be used in cases of liver cancer where surgical resection can be tolerated and the tumor fits specific criteria, i.e., Milan criteria (4).

Signaling pathways are complex processes of signal transduction involving the mutual activation of a protein cascade transmitting signals from the cell surface to the cytoplasm and the nucleus (5). In recent decades, emerging studies have greatly improved our understanding of liver tumorigenesis through investigation of a series of signaling pathways including PI3K/AKT. Cell signaling receptors, intracellular secondary messengers/molecules and transcription factors are essential components for signaling pathways, and the protein-protein interactions (PPIs) among these components act as connectors that mediate signal transduction from one step to the following within a single signaling pathway, and act as transmitters that play an important role in the crosstalk of several signaling pathways (6). PPIs refer to the intentional physical contacts established between two or more proteins as a result of biochemical events and/or electrostatic forces (7). Proteins rarely act alone at both cellular and systemic levels. A number of essential molecular processes are performed by molecular machines that are constructed from a large number of protein components organized by their PPIs. PPIs have been largely investigated in signal transduction and aberrant PPIs in these signaling pathways are considered the basic events of 
liver cancer. Targeting these important PPIs may be useful for the treatment of liver cancer.

In the present review, we focus on PPIs in the PI3K/AKT and other important signaling pathways in liver cancer. The potential antitumor therapies targeting these pivotal PPIs and the strategies of how to investigate and analyze PPIs are also assessed.

\section{PI3K/AKT signaling pathway}

The PI3K/AKT pathway is an intracellular pathway that is involved in cell cycle, growth, survival, proliferation and migration. Enhanced PI3K/AKT activities have been reported in many human cancer types, including cancers of colon, breast, brain, liver, stomach and lung (8). The PI3K/AKT signaling pathway can be activated by four main types of sensors: the receptor tyrosine kinases (RTKs), cytokines, $\mathrm{G}$ protein-coupled receptors and the integrins (9-11). These four types of sensors bind with their cofactors and activate downstream kinases in the PI3K families. PI3K, by transferring a phosphoryl group, converts phosphatidylinositol 4,5-diphosphate (PIP2) to phosphatidylinositol 3,4,5-triphosphate (PIP3) (12). PIP3 can interact with AKT which contains pleckstrin homology $(\mathrm{PH})$ domain on the inner surface of the plasma membrane, resulting in conformational changes of these proteins (13). Following binding to PIP3 at the membrane, AKT can then be phosphorylated by phosphoinositide-dependent kinase 1 (PDK1) at threonine 308 or be phosphorylated by the mammalian target of rapamycin complex (mTORC) at serine $473(14,15)$. Fully phosphorylated AKT can directly interact with $>100$ proteins including the mTORC, Bcl-2-associated death promoter (BAD), caspase-9, various forkhead box protein O (FOXO) proteins, glycogen synthase kinase $3 \beta$ (GSK3 $\beta$ ), mouse double minute 2 homolog (MDM2) and tuberous sclerosis 1 (TSC1) (16).

\section{PPIs between PI3K/AKT and other signaling pathways}

AKT, the core protein in the PI3K/AKT signaling pathway, can physically interact with proteins in other signaling pathway. Thus, activity of the PI3K/AKT signaling pathway in liver cancer can directly affect the activities of other signaling pathways, such as Hippo/YAP, NF- $\kappa \mathrm{B}, \mathrm{Wnt} / \beta$-catenin, Notch, p53, JAK/STAT and MAPK/ERK signaling pathways.

AKT is shown to physically bind to the proteins, IKKA and IKKB in the NF- $\mathrm{BB}$ signaling pathway. AKT phosphorylates IKKA on threonine (Thr) 23 , thereby activating the $\mathrm{NF}-\kappa \mathrm{B}$ signaling pathway and subsequently inducing key immune and inflammatory responses $(17,18)$. In addition, IKKB is a direct target of AKT, and activation of the AKT/IKKB signal is closely correlated with the anti-apoptotic and pro-cell survival function of NF- $\kappa \mathrm{B}$ signaling in breast cancer cells (19). Similarly, the activation of AKT can directly induce activation of the NF- $\mathrm{NB}$ signaling pathway and eventually suppress apoptosis in liver cancer cells $(20,21)$. By contrast, the inactivation of AKT strongly prevents NF- $\kappa \mathrm{B}$ transcription factor $\mathrm{p} 65$ from entering the nucleus, the site at which p65 exerts its effects, and subsequently induces apoptosis in the HepG2 liver cancer cell line (22).
AKT is also capable of interacting and phosphorylating MST1/2 kinases, key components of the Hippo/YAP signaling pathway, on Thr 120. Such effects reduce the inhibitory impact of MST1/2 on the activity of YAP, the terminal effector of the Hippo/YAP signaling pathway, and thereby enhance AKT-maintained cell survival signaling (23).

AKT was found to have the ability to activate the Wnt/ $\beta$-catenin signaling pathway by directly interacting with GSK3 $\beta$, a natural inhibitor of $\beta$-catenin. AKT represses GSK3 $\beta$ by initiating its phosphorylation at serine 9 and vice versa (24). The phosphorylation of $\beta$-catenin via GSK3 $\beta$ is then repressed, which facilitates $\beta$-catenin translocation from the cytoplasm into the nucleus and $\mathrm{Wnt} / \beta$-catenin signaling is eventually activated $(25,26)$. Notably, the close relationship between the activation of PI3K/AKT and the upregulation of Wnt/ $\beta$-catenin activity was also observed in liver cancer (27). Additionally, promoted liver cancer cell growth and proliferation was maintained by the PI3K/AKT and Wnt/ $\beta$-catenin signaling pathways (28). The interaction between PI3K/AKT and $\mathrm{Wnt} / \beta$-catenin is also critical for regulation of the cell cycle and epithelial-mesenchymal transition (EMT) during tumor formation, as following the respression of GSK3 $\beta$ by AKT, Wnt/ $\beta$-catenin signaling down-stream effectors, such as cyclin D1, Snail and Mucin 1, are affected (29-31).

The MAPK/ERK is another important signaling pathway involved in a variety of cell processes including proliferation, differentiation, migration and survival. The MAPK/ERK signaling pathway is frequently activated in liver cancer often due to activating mutations or amplification of several components such as Ras, Raf and MEK $(32,33)$. Notably, emerging evidence suggests that AKT is also capable of activating the MAPK/ERK signaling pathway via interaction with MAPK/ERK signaling components. Firstly, Raf, MAP3K5, MAP3K8 and MAP3K11 are activated by AKT via phosphorylation (34-37). Secondly, MAPK2K4 is phosphorylated by AKT on serine 78 to suppress apoptosis (38). Additionally, MAPK14/p38 is directly bound to and activated by AKT, thus establishing a crosstalk between the MAPK/ERK and PI3K/AKT signaling pathways (39). In addition to the direct binding to the MAPK/ERK components, AKT can physically interact with certain proteins, which can indirectly influence MAPK/ERK signaling activity. For example, AKT is known to interact with MAPK8IP1/JIP1, a regulator of MAPK8/ $\mathrm{JNK}$, to control inflammatory responses, cell proliferation and apoptosis (40). Furthermore, the downstream effectors of AKT, such as mTOR and GSK3 $\beta$ bind to the core regulator in the MAPK/ERK signaling pathway. For example, GSK3 $\beta$ physically interacts with and activates MAP3K1 in vitro and in vivo to regulate cell differentiation and apoptosis (41).

PPIs are also important for the crosstalk between PI3K/AKT and tumor suppressor p53 signaling pathways. AKT can directly interact with and regulate MDM2, one of the most well-characterized oncogenic ubiquitin E3 ligases that negatively regulates p53 transcription activity. Activation of AKT leads to phosphorylation of MDM2 on Ser 166 and 186, whereas inhibition of AKT decreases such phosphorylated levels $(42,43)$. Phosphorylation of MDM2 decreases the protein levels of $\mathrm{p} 53$, thereby suppressing apoptosis in liver cancer cells (44). When the cells were pretreated with Wortmannin, a well-known PI3K/AKT inhibitor, to suppress 
AKT activation, both the upregulation of phosphorylation of MDM2 and downregulation of p53 were reversed in the HepG2 liver cancer cell line (45).

PPIs between PI3K/AKT and Notch signaling have also been identified (46). Upregulation of AKT is shown to induce the activation of Notch signaling (47), and these two signaling pathways are always activated in liver cancer (48). The simultaneous inhibition of these two pathways has been shown to be an effective option aiming at cancer in clinical treatment (49), suggesting the close relationship between PI3K/AKT and Notch signaling during tumorigenesis.

As for the JNK/STAT signaling pathway, the downstream effector of AKT, mTOR, has been shown to physically interact with STAT1 and STAT3 and regulates the transcription activity of these two transcription factors $(50,51)$.

In general, according to the results of the aforementioned studies, AKT can physically bind to a series of core protein in different signaling pathways and activation of the AKT signaling pathway can directly or indirectly lead to the activation of several other signaling pathways. Thus, we suggest that PI3K/AKT is central to the complex signaling network involved in liver as well as in other organ tumorigenesis.

\section{Proteins that physically interact with AKT as its downstream effectors in liver cancer}

In liver cancer, deregulated PI3K/AKT signaling pathway often leads to uncontrolled cell growth, metabolism, survival, metastasis and tumor formation. The PPI between AKT and mTOR and the mechanism associated with this interaction has been largely investigated in liver cancer. mTOR exists in two different complexes, mTOR complex 1 (mTORC1) and mTORC2. The mTORC2 complex directly phosphorylates AKT on Ser473 and AKT conversely phosphorylates mTORC1 at two COOH-terminal sites (Thr2446 and Ser2448) (14,53). p70S6 kinase and translational repressor protein 4E-binding protein 1 (4EBP1), the downstream effector of mTOR, are then phosphorylated by mTOR and regulate the translation of several important proliferative and angiogenic factors, such as c-Myc, cyclin D1, hypoxia-inducible factor (HIF) $1 \alpha$ and vascular endothelial growth factor (VEGF) (53-55), which are associated with tumor progression in liver cancer. The deregulated expression of mTOR signaling effectors ia present in $40-50 \%$ of HCC and activation of mTOR is correlated with poor prognosis and recurrence in $\mathrm{HCC}(56,57)$.

FOXO1 is also regarded as an AKT downstream effector. $\mathrm{AKT}$ has been proven to interact with FOXO1, which is a transcription factor involved in the regulation of gluconeogenesis and glycogenolysis via insulin signaling, and FOXO1 is also central to the decision for a preadipocyte to commit to adipogenesis (58). When FOXO1 is phosphorylated by AKT on Thr24, Ser256 and Ser319, it is spatially excluded from the nucleus and is then readily ubiquitinated and degraded (59). The phosphorylation of FOXO1 by AKT also impairs FOXO1induced hepatic glucose production through a reduction in the transcription of glucose 6-phosphatase (G6PC) gene (60).

Additionally, BAD has been shown to physically interact with AKT. BAD protein is a pro-apoptotic member of the Bcl-2 gene family, which is involved in initiating apoptosis. Dephosphorylated BAD forms a heterodimer with $\mathrm{Bcl}-2$ or Bcl-xL, represses them and thus initiates Bax/Bak-triggered apoptosis. When BAD is phosphorylated by AKT, it forms the BAD-14-3-3 protein heterodimer, allowing Bcl-2 to inhibit Bax-induced apoptosis (61). Inactivation of AKT removes its inhibitory effect to BAD, which may also decrease the levels of anti-apoptotic Bcl-2 and Bcl-XL proteins, and eventually lead to mitochondria-induced apoptosis in tumor cells (44). In liver cancer cells, AKT-mediated inhibitory effects on BAD-induced mitochondrial apoptotic signals were also observed (62).

AKT interacts with and activates S-phase kinase-associated protein 2 (Skp2) through phosphorylation of this protein on Ser72 $(63,64)$. Skp2 behaves as an oncogene, and overexpression of this protein is frequently observed in human cancer progression and metastasis (wenxian). In human liver cancer cell lines and a murine liver cancer model, overexpression of AKT also led to the overexpression of Skp2 (65), indicating Skp2 may act as a downstream oncogenic effector of AKT during liver tumorigenesis.

Androgen receptor (AR) is activated by teh binding of androgenic hormones testosterone or dihydrotestosterone in the cytoplasm, and exerting its nuclear receptor function in the nucleus (66). AKT is capable of preventing AR from activation by androgen via the phosphorylation of AR on Ser210 and Ser790 allowing AKT to suppress androgen-induced apoptosis (67). AR has been shown to promote the initiation and development of liver cancer during the early stage of the disease but to suppress liver cancer cell invasion during the later stages of the disease (68). Evidence from Nie et al (69) indicates that the activation of AKT directly impacts AR to inhibit apoptosis in HCC cells, suggesting the function of downstream AR responds to the function of upstream AKT.

In addition to the PPIs between AKT and the proteins described above, AKT can also interact with other proteins that are found to play significant roles in liver cancer. These proteins include T-cell leukemia/lymphoma protein 1 (TCL1) $(70,71)$, breast cancer type 1 susceptibility protein (BRCA1) (72), vimentin (73), integrin-linked kinase (ILK) (74,75), and heat shock protein 27 (HSP27) (76). The proteins that AKT can bind to liver cancer are provided in Table I.

\section{AKT-involved PPIs revealed in other models}

A number of novel AKT-involved PPIs have been identified in other cancer types. For example, Nam et al (77) found that Cdc-2-like kinase 2 (CLK2) is phosphorylated by AKT at Ser34 and Thr127 in vitro and in vivo. This type of phosphorylation significantly increased cell growth whereas it inhibits cell apoptosis in HeLa cells. Snaill, a transcriptional factor essential for triggering EMT, can directly interact and thus enhance AKT-induced open chromatin around the Snaill-binding site within the E-cadherin promoter in different cancer cells (78). Sirtuin-6 (Sirt6), a tumor suppressor that plays negative roles on DNA repair, telomere maintenance, glycolysis and inflammation, is directly inhibited by AKT through phosphorylation and subsequent degradation by MDM2, and this type of PPI between Sirt6 and AKT promotes tumorigenesis in breast cancer (79). Cyclin-dependent kinase inhibitor 1C (CDKN1C), an inhibitor of cyclin-dependent kinases, is pivotal in regulating cell cycle progression. AKT phosphorylates and inhibits 
Table I. AKT-involved PPIs in homo sapiens.

Interactor

Experimental evidence

BAD BCL2-associated agonist of cell death; promotes cell death. Successfully competes for the binding to Bcl-X(L), Bcl-2 and Bcl-W, thereby affecting the level of heterodimerization of these proteins with BAX

BRCA1 Breast cancer 1, early onset; the BRCA1-BARD1 heterodimer coordinates a diverse range of cell pathways such as DNA damage repair, ubiquitination and transcriptional regulation to maintain genomic stability

CHUK Conserved helix-loop-helix ubiquitous kinase; acts as part of the IKK complex in the conventional pathway of $\mathrm{NF}-\kappa \mathrm{B}$ activation and phosphorylates inhibitors of NF- $\mathrm{KB}$ thereby leading to the dissociation of the inhibitor/ $\mathrm{NF}-\kappa \mathrm{B}$ complex and ultimately the degradation of the inhibitor

CREB1 CAMP responsive element binding protein 1; this protein binds the cAMP response element (CRE), a sequence present in many viral and cellular promoters. CREB stimulates transcription on binding to the CRE

FOXO1 Forkhead box O1; transcription factor

Biochemical Activity (168-170)

FOXO4 Forkhead box O4; transcription factor

GSK3 $\beta \quad$ Glycogen synthase kinase $3 \beta$; participates in the Wnt signaling pathway. Involved in the hormonal control of several regulatory proteins including glycogen synthase, MYB and the transcription factor JUN

IKKB Inhibitor of $\kappa$ light polypeptide gene enhancer in B-cells, kinase $\beta$; acts as part of the IKK complex in the conventional pathway of $\mathrm{NF}-\kappa \mathrm{B}$ activation and phosphorylates inhibitors of $\mathrm{NF}-\kappa \mathrm{B}$ thus leading to the dissociation of the inhibitor/NF- $\mathrm{B}$ complex and ultimately the degradation of the inhibitor

CSBP One of the major pre-mRNA-binding proteins. Binds tenaciously to poly $(\mathrm{C})$ sequences. Likely to play a role in the nuclear metabolism of hnRNAs, particularly for pre-mRNAs that contain cytidine-rich sequences

MDM2 Mdm2 p53 binding protein homolog (mouse); inhibits TP53/p53and TP73/p73-mediated cell cycle arrest and apoptosis by binding its transcriptional activation domain. Functions as a ubiquitin ligase E3, in the presence of E1 and E2, towards p53 and itself

MTOR Mechanistic target of rapamycin (serine/threonine kinase); kinase subunit of mTORC1 and mTORC2, which regulate cell growth and survival in response to nutrient and hormonal signals

NEDD4 Essential E3 ubiquitin-protein ligase which accepts ubiquitin from an E2 ubiquitin-conjugating enzyme in the form of a thioester and then directly transfers the ubiquitin to targeted substrates

PTEN Phosphatase and tensin homolog; tumor suppressor. Acts as a dual-specificity protein phosphatase, dephosphorylating tyrosine-, serine- and threonine-phosphorylated proteins

Affinity Capture-Western (171)

Biochemical Activity (172)

Reconstituted Complex (171)

Biochemical Activity (173)

Reconstituted Complex (75,174-176)

Affinity Capture-Western (19)

Affinity Capture-Western (39)

Biochemical Activity $(39,177)$

Reconstituted Complex (39)

Affinity Capture-Western $(173,178)$

Biochemical Activity $(179,180)$

Affinity Capture-Western (181)

Biochemical Activity $(14,182,183)$

Reconstituted Complex (52)

Affinity Capture-Western (184)

Biochemical Activity (185)

Affinity Capture-Western (186) 
Table I. Continued.

Interactor

Experimental evidence

RICTOR RPTOR-independent companion of MTOR, complex 2; subunit

Affinity Capture-Western (187)

of mTORC2, which regulates cell growth and survival in response to hormonal signals. mTORC2 is activated by growth factors, however, in contrast to mTORC1, seems to be nutrient- insensitive.

SIRT1 Sirtuin (silent mating type information regulation 2 homolog) 1 (S. cerevisiae); NAD-dependent protein deacetylase, which regulates processes such as apoptosis and muscle differentiation by deacetylating key proteins.

SKP2 S-phase kinase-associated protein 2 (p45); substrate recognition component of a SCF (SKP1-CUL1-F- box protein) E3 ubiquitin-protein ligase complex that mediates the ubiquitination and subsequent proteasomal degradation of target proteins involved in cell cycle signal progression, transduction and transcription.

MST2 Stress-activated, pro-apoptotic kinase which, following caspase-cleavage, enters the nucleus and induces chromatin condensation followed by internucleosomal DNA fragmentation. Phosphorylates NKX2-1 (by similarity). Phosphorylates and activates LATS1 and LATS2

MAPK8IP1 The JNK-interacting protein (JIP) group of scaffold proteins selectively mediates JNK signaling by aggregating specific components of the MAPK cascade to form a functional JNK signaling module.

MAPK14 Mitogen-activated protein kinase 14; responds to activation by environmental stress, pro- inflammatory cytokines and lipopolysaccharide (LPS) by phosphorylating a number of transcription factors, such as ELK1 and ATF2 and several downstream kinases, such as MAPKAPK2 and MAPKAPK5.

MAPKK4 Mitogen-activated protein kinase kinase 4; dual specificity kinase that activates the JUN kinases MAPK8 (JNK1) and MAPK9 (JNK2) as well as MAPK14 (p38), but not MAPK1 (ERK2) or MAPK3 (ERK1)

MAPKKK5 Mitogen-activated protein kinase kinase kinase 5; component of a Biochemical Activity $(85,188,189)$

Reconstituted Complex (190)

Affinity Capture-Western (191)

Biochemical Activity (191)

Affinity Capture-Western (62)

Biochemical Activity (193)

Co-localization (64)

Reconstituted Complex (64)

Affinity Capture-Western $(193,194)$

Biochemical Activity $(193,194)$

Affinity Capture-Western (161)

Biochemical Activity (40)

Affinity Capture-Western (39)

Biochemical Activity $(39,177)$

Reconstituted Complex (39)

Affinity Capture-Western (38)

Biochemical Activity $(38,161)$

Affinity Capture-Western (35) protein kinase signaling transduction cascade. Phosphorylates and activates Biochemical Activity (35) MAP2K4 and MAP2K6, which in turn activate the JNK and p38 MAP kinases, respectively.

SNAIL1 Snail homolog 1 (Drosophila) gene; this protein has many roles during post-implantation development. It is involved in embryonic mesoderm formation and its maintenance and may also be involved in chondrogenesis and in epithelial-mesenchymal inductive interactions.

SIRT6 Sirtuin (silent mating type information regulation 2 homolog) 6 (S. cerevisiae); NAD-dependent protein deacetylase. Has deacetylase activity towards 'Lys-9' and 'Lys-56' of histone H3. Modulates acetylation of histone $\mathrm{H} 3$ in telomeric chromatin during the $\mathrm{S}$ phase of the cell cycle.

MAPKKK8 Mitogen-activated protein kinase kinase kinase 8; required for TLR4 activation of the MEK/ERK pathway. Able to activate $\mathrm{NF}-\kappa \mathrm{B} 1$ by stimulating proteasome-mediated proteolysis of NF- $\kappa \mathrm{B} 1 / \mathrm{p} 105$. Plays a role in the cell cycle.

MAPKKK11 Mitogen-activated protein kinase kinase kinase 11; activates the JUN $\mathrm{N}$-terminal pathway. Required for serum-stimulated cell proliferation and for mitogen and cytokine activation of MAPK14 (p38), MAPK3 (ERK) and MAPK8 (JNK1).

Affinity Capture-Western (78)

Biochemical Activity (78)

Affinity Capture-Western (79)

Biochemical Activity (79)

Affinity Capture-Western (37)

Biochemical Activity (37)

Affinity Capture-Western (34)

Reconstituted Complex (34) 
Table I. Continued.

Interactor

Experimental evidence

AR Androgen receptor; steroid hormone receptors are ligand-activated transcription factors that regulate eukaryotic gene expression and affect cell proliferation and differentiation in target tissues.

Notch1 Notch homolog 1, translocation-associated (Drosophila); functions as a receptor for membrane-bound ligands Jagged1, Jagged2 and Delta1 to regulate cell-fate determination. Following ligand activation through the released notch intracellular domain (NICD) it forms a transcriptional activator complex with RBP-J $\kappa$ and activates genes of the enhancer of split locus.

\begin{abstract}
Affinity Capture-Western: an interaction is inferred when a bait protein is affinity-captured from cell extracts by either polyclonal antibody or epitope tag and the associated interaction partner identified by western blot analysis with a specific polyclonal antibody or second epitope tag. This category is also used if an interacting protein is visualized directly by dye stain or radioactivity. Note that this differs from any co-purification experiment involving affinity capture in that the co-purification experiment involves at least one extra purification step to eliminate potential contaminating proteins. Biochemical Activity: an interaction is inferred from the biochemical effect of one protein on another, for example, GTP-GDP exchange activity or phosphorylation of a substrate by a kinase. The bait protein executes the activity on the substrate hit protein. A modification value is recorded for interactions of this type with the possible values phosphorylation, ubiquitination, sumoylation, dephosphorylation, methylation, prenylation, acetylation, deubiquitination, proteolytic processing, glucosylation, Nedd(Rub1)ylation, deacetylation, no modification, and demethylation. Reconstituted Complex: an interaction is detected between purified proteins in vitro. Co-localization: interaction inferred from two proteins that co-localize in the cell by indirect immunofluorescence only when in addition, if one gene is deleted, the other protein becomes mis-localized. Includes co-dependent association of proteins with promoter DNA in chromatin immunoprecipitation experiments. The data are from BioGRID (http://thebiogrid.org).
\end{abstract}

CDKN1C on Ser 282 or Thr310, and then promotes cell proliferation, transformational activity and tumorigenicity in breast cancer cells (80). Although studies have mainly focused on how AKT regulates activities of other proteins, few have discussed how other proteins regulate AKT. Zeng et al (81) reported Jade-1 is a novel tumor suppressor that is bound to the catalytic domain and the C-terminal regulatory tail of AKT. This PPI inhibits AKT kinase activity and reduced Jade-1 expression in clear-cell renal cell carcinoma and is regarded as a poor prognostic factor. Cylindromatosis (CYLD) is a directly deubiquitinating enzyme that triggers deubiquitination of K63-linked ubiquitination and inactivation of AKT. CYLD deficiency releases its inhibition to AKT and thereby promotes cell proliferation, glucose uptake and growth of prostate tumors (82). These AKT-involved PPIs were important in tumor initiation and progression in other cancer types. However, whether and how these PPIs are critical during liver tumorigenesis remains largely unclear. Nevertheless, the role of these PPIs as novel therapeutic targets in clinical treatment remains to be investigated.

\section{Therapies targeting PI3K/AKT-involved PPIs}

Since the PI3K/AKT signaling pathway is a crucial pathway in liver cancer formation and progression, targeting PI3K/AKT pathway, these PI3K/AKT-involved physical PPIs in particular are novel aspects in the clinical treatment of liver cancer. mTOR inhibitors can abolish the interaction between AKT and mTOR by inhibiting the phosphorylation of AKT on Ser 473 (83-85). As PPI between AKT and mTOR are important in liver cancer, the use of mTOR inhibitors, such as sirolimus, can significantly reduce the recurrence of liver cancer in the post-liver transplantation patient population (86). In a recent meta-analysis including 474 patients, the 1-, 3- and 5-year recurrence-free survival (RFS) and overall survival (OS) was considerably improved for the sirolimus group in comparison with the calcineurin inhibitors (CNIs) group. Lower recurrence, lower recurrence-associated mortality and lower overall mortality were observed in the sirolimus group compared to the CNIs group (87). Other second-generation mTOR inhibitors, such as everolimus, Pp242, OSI027, CC-223 and AZD8055, have similar antitumor efficacy in liver cancer cell lines and xenograft models (88). A phase $1 / 2$ study including 28 patients revealed that everolimus is well tolerated in patients with advanced liver cancer, and $10 \mathrm{mg} /$ day was defined as the phase 2 dose (89). In another cohort of 36 patients, everolimus was observed to repress cancer progression in patients with advanced liver cancer when used at a maximum tolerated dose of $70 \mathrm{mg}$ weekly $(88,90)$.

In addition to the therapy targeting mTOR, which may interrupt the PPI between mTOR and AKT, some drugs have been identified to simultaneous inhibit more than one signaling pathway. For example, hydroxytyrosol is capable of inhibiting cell proliferation and inducing $\mathrm{G} 2 / \mathrm{M}$ cell cycle arrest and apoptosis in HCC cells by suppressing the PI3K/ AKT and NF- $\mathrm{KB}$ signaling pathways (91). OSU-A9, a potent indole-3-carbinol-derived $\mathrm{PI} 3 \mathrm{~K} / \mathrm{AKT} / \mathrm{NF}-\kappa \mathrm{B}$ signaling pathway inhibitor, can induce apoptosis by inactivating PI3K/ AKT/NF- $\mathrm{BB}$ signaling and killing HCC cells (92). NS398, a selective cyclooxygenase-2 (Cox2) inhibitor and simvastatin, a 3-hydroxy-3-methylglutaryl coenzyme A reductase inhibitor, were previously simultaneously used and this co-administration significantly reduced the activity of the PI3K/AKT and $\mathrm{NF}-\kappa \mathrm{B}$ signaling pathways, leading to inhibited liver cancer 


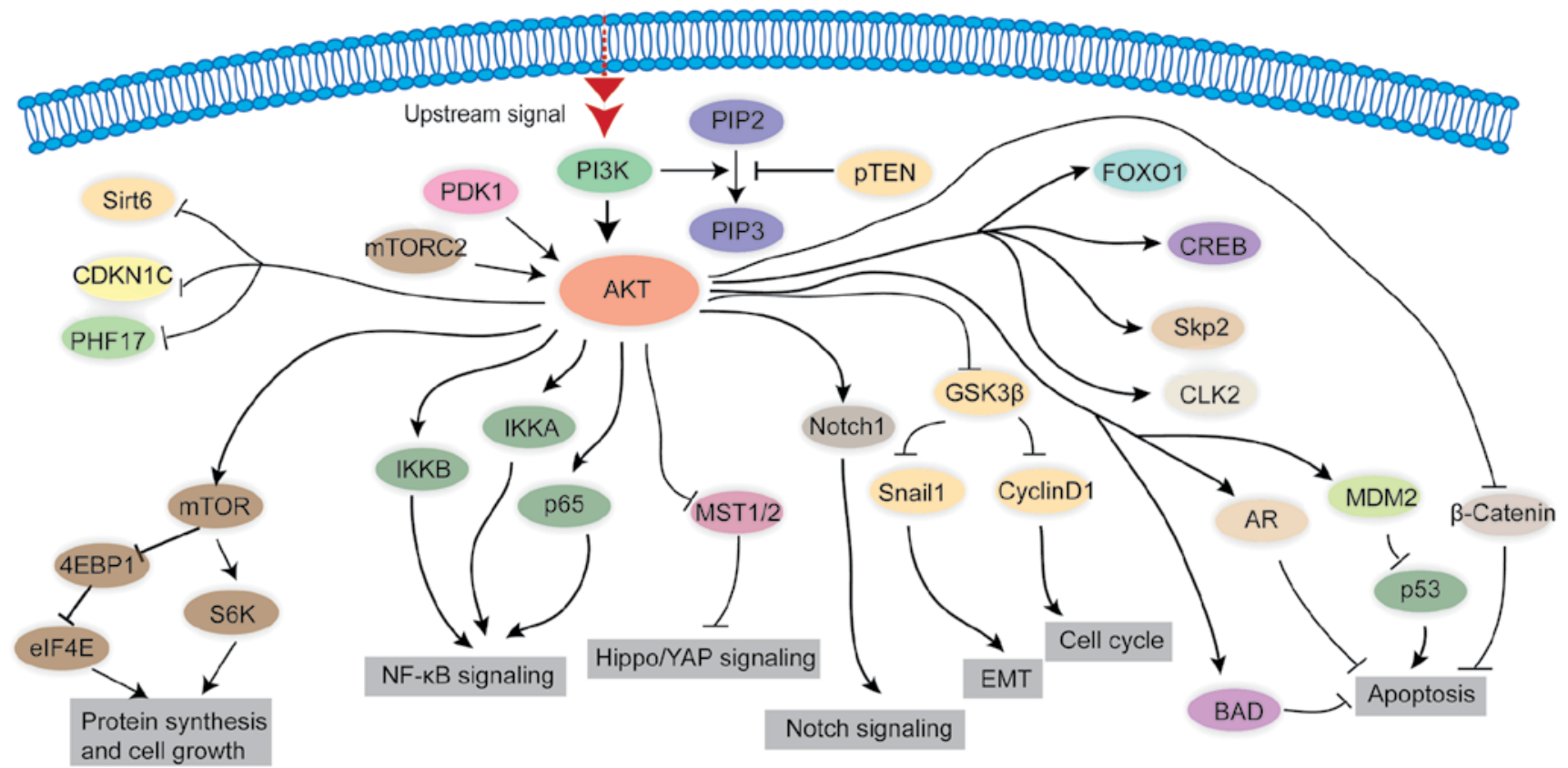

Figure 1. PI3K/AKT-involved PPIs during tumor formation. Image of direct PPIs between AKT and key indicated proteins within certain signaling pathways The potential therapeutic targets of certain drugs are shown.

cell proliferation and induction of apoptosis (93). Baicalein is another drug that plays a negative role against liver cancer by targeting AKT and $\beta$-catenin in clinical treatment (94). An in vitro study showed that Baicalein has significant cytotoxicity against liver cancer cells but moderate cytotoxicity against immortalized human hepatocytes, suggesting Baicalein is an ideal drug that is less harmful to normal cells as compared to cancer cells. Baicalein has the ability to induce G0/G1-phase arrest in liver cancer cells by inhibiting PI3K/AKT signaling and promoting degradation of $\beta$-catenin, the key factor of Wnt/ $\beta$-catenin signaling pathway. An in vivo study also demonstrated that Baicalein impairs tumor growth in a xenograft mouse model by inhibiting PI3K/AKT and $\beta$-catenin. Through a similar mechanism against PI3K/AKT and $\beta$-catenin, BCT-100, a new recombinant human arginase, has been revealed to inhibit cell proliferation and enhance caspase-dependent cell apoptosis (95). PI3K/AKT, mTORC1 and MEK signaling can be simultaneously inhibited in vitro and in vivo by a novel 2-pyrimidyl-5-amidothiazole compound, DC120. Thus, this drug is able to suppress proliferation but also induce apoptosis in liver cancer cells (96).

Other PPIs can also be treated as potential therapeutic targets. Vassilev et al (97) developed a class of small molecules, known as Nutlins, that can occupy the p53-binding pocket within the MDM2 protein, thereby blocking the PPI between MDM2 and p53. This effect facilitates the p53 tumor suppressor network to inhibit transformative phenotype of human cancer cells in vitro and in vivo. Curcumin has also been found to inhibit MDM2 by targeting PI3K/mTOR/ETS2 in several cancer cell lines (98).

The treatment of ANISpm, a novel 3-amino-naphthalimidespermine conjugate, results in the inactivation of PI3K/AKT signaling followed by dissociation of BAD from BAD-Bcl complexes and the induction of Bcl-mediated apoptosis in liver cancer cells (99). The treatment of 3-nitro-naphthalimide and nitrogen mustard conjugate is another potential therapy that can induce apoptosis in liver cancer cells through the inhibition of PI3K/AKT signaling (100).

Macromolecules (macrodrugs) can be developed that interfere with PPIs by binding with high affinity and specificity to contact surfaces. Although macrodrugs have inherent problems of bio-distribution and delivery to target cells in patients, their efficacies on the inhibition of cancers suggest that efforts to achieve the goal of clinical use should be pursued (101). Targeting physical PPIs especially PI3K/AKT-involved PPIs may become a new aspect in the clinical treatment of liver cancer (Fig. 1).

\section{PPIs in other signaling pathways}

There are a number of signaling pathways that can play oncogenic roles in liver cancer. For example, the Notch signaling pathway is a highly conserved pathway in most multicellular organisms (102). The Notch system comprises four types of transmembrane Notch receptors (Notch-1, -2, -3 and -4), and two types of ligands, Serrate/Jagged (Jag-1 and -2) and Deltalike (Dll-1, -3 and -4) (103). Extracellular epidermal growth factor (EGF)-like repeats in Notch receptors can interact with the delta serrate LAG-2 (DSL) domain in the ligands. Following ligand binding to the receptors, the extracellular domain of Notch receptors is cleaved by the $\gamma$-secretase complex, and the Notch intracellular domain (NICD) is released. NICD then shuttles into the nucleus and interacts with CBF1/Drosophila $\mathrm{Su}(\mathrm{H}) / C$. elegans LAG-1 (CSL)-binding proteins, which are also known as recombination signal binding protein immunoglobulin $\mathrm{J}_{\kappa}(\mathrm{RBP}-\mathrm{J} \kappa)$. The co-repressors of RBP-J $\kappa$ are then replaced and the expression of a set of Notch target genes is activated (104). Notch proteins have been shown to interact with a family of mastermind-like transcriptional coactivators (MAML1, MAML2 and MAML3). MAML1 binds to the 
ankyrin repeat domain of the four mammalian Notch receptors, forms a DNA-binding complex with NICD and RBP-Jк, and amplifies the Notch-induced transcription of HES1 (105). A dominant negative form of MAML can significantly reduce the proliferation of liver cancer cells (106). By contrast, there are also some PPIs that can inhibit Notch signaling. Protein Numb can interact with Notch receptors and antagonize Notch signaling. Mechanically, Numb recruits components of the ubiquitination machinery to the Notch receptor and thereby facilitating ubiquitination of Notch1 at the membrane and promoting the degradation of NICD. Numb acts as a tumor suppressor, and its function of inhibiting tumor cell proliferation occurs largely through the suppression of Notch signaling. In liver cancer cells, the downregulation of Numb is positively associated with activation of Notch signaling-induced cell proliferation and growth (107).

Hedgehog $(\mathrm{Hh})$ is another important pro-tumorigenic signaling pathway that was first identified by the Nobel laureates Nüsslein-Volhard and Wieschaus through mutagenesis screening assays in Drosophila (108). In mammals, hedgehog homologues include the Desert hedgehog (DHh), Indian hedgehog ( $\mathrm{IHh}$ ) and Sonic hedgehog ( $\mathrm{SHh})$. Hh proteins are synthesized as $\sim 45-\mathrm{kDa}$ precursors, followed by modifications at the amino-terminus with palmitic acids and carboxy-terminus with cholesterol groups $(109,110)$. Hh proteins can bind to the Protein patched homolog $(\mathrm{PTCH})$ receptor, which is a 12-span transmembrane protein $(111,112)$. PTCH is also a negative regulator in Hh signaling because it can inhibit the activity of the 7-pass transmembrane receptor-like protein smoothened (SMO) (113). Binding of Hh proteins to PTCH leads to loss of the inhibitory activity of PTCH on SMO, which initiates an intracellular signaling cascade by releasing GLI proteins, terminal effectors of $\mathrm{Hh}$ signaling. These GLI proteins then enter into the cell nucleus to activate the transcription of $\mathrm{Hh}$ signaling target genes. The GLI proteins found in mammals include GLI1, GLI2 and GLI3. Numerous genes have been found to be regulated by these three GLI proteins. Overactivation of $\mathrm{Hh}$ signaling is responsible for proliferative diseases, including cancer. In 2006, Hh signaling was firstly studied in HCC and investigators identified that SMO and GLI1 proteins are overexpressed in established liver cancer cell lines and liver cancer tissue samples. Furthermore, an increase in the stoichiometric ratio of SMO to PTCH mRNA levels in liver cancer was revealed to correlate with tumor size and be treated as a prognostic marker of liver cancer $(114,115)$. GLI1 expression in HCC tissues was observed to be negatively associated with diseasefree and overall survival. Overexpression of GLI1 promotes the proliferation, viability, colony formation, migration and invasion of liver cancer cells, while silencing GLI1 expression in liver cancer cells leads to the opposite output (116). The protein zinc finger of the cerebellum 1 (ZIC1) interacts with GLI1 and repress the activity of GLI1 (117), thus ZIC1 is regarded as a tumor suppressor. In liver cancers, methylation frequencies of ZIC1 promoter are significantly higher than those in the corresponding non-cancerous tissues. Moreover, patients whose ZIC1 promoters are methylated have poorer survival rates than those without such methylation (118).

The Hippo/YAP signaling pathway has become a hot research topic. This pathway was first identified in Drosophila and controls organ size through the regulation of cell proliferation and apoptosis. All of the core components of the Hippo/YAP signaling pathway are conserved in mammalians. By phosphorylating the terminal transcriptional regulator of the Yes-associated protein (YAP) signaling pathway, large tumor suppressor kinase (LATS) promotes the PPI between YAP and 14-3-3 proteins, which helps to anchor YAP in the cytoplasm and prevents its transportation into the nucleus. When the upstream Hippo signaling is inactivated, YAP can translocate into the nucleus and bind to several transcription factors including p73, runt-related transcription factor 2 (Runx2) and TEA-domain family member (TEAD) protein families (119). A series of recent studies have demonstrated that the core components of the Hippo/YAP signaling pathway are important for liver tumorigenesis. Approximately $50 \%$ of human HCCs show aberrant expression and nuclear localization of YAP (120), with 30\% HCCs showing low phosphorylation of YAP on Ser127, a hallmark of the inactivation of YAP (121). PPIs between YAP and other proteins have gradually been identified, including SMADs (122), p73 (123), ErbB4 (124), TEADs (119), RUNX (125), angiomotins (AMOTs) (126128), zona occludens $1 / 2$ (ZO1/2) (129) and LATS1/2 (130). In liver cancer, these PPIs play pivotal roles in promoting or inhibiting tumor formation. LATS kinases inhibit YAP function by promoting the cytoplasmic retention of YAP by phosphorylating YAP on Ser127 (131). A significant decrease in the expression and activity of LATS kinases is evident in HCC and CCC (132). YAP has been shown to interact with the TEAD family of transcription factors and upregulate genes that promote cell growth and inhibit apoptosis $(133,134)$. The YAP-TEAD complex is important in YAP-overexpressing cancers and disruption of the YAP-TEAD interaction may provide an important approach for the treatment of liver cancer. The treatment of various types of cancer with verteporfin (VP) to disrupt the PPI between YAP and TEAD was suggested to become a new approach in clinical treatment (135). In addition to TEAD, YAP has been found to interact with tight junction proteins angiomotin (AMOT) and zona occludens-2 (ZO-2). AMOT acts as a YAP cofactor, preventing YAP phosphorylation and increasing its activity towards a specific set of genes that facilitate tumorigenesis in liver cancer. However, the functional role of PPI between YAP and ZO-2 in liver cancer remains to be investigated. These direct PPIs in the Notch, hedgehog, and Hippo/YAP pathways that are associated with liver cancer are shown in Fig. 2.

\section{How to investigate and analyze PPIs}

Methods that detect PPIs can be classified into three categories, i.e., in vitro, in vivo and in silico methods. For in vitro methods, a given procedure is carried out in a controlled environment outside a living organism; for in vivo methods, a given procedure is carried out inside a living organism; and for in silico methods, the procedure is performed in a computer simulation (136). In vitro methods for detecting PPIs include affinity chromatography (137), X-ray crystallography (138), co-immunoprecipitation (139), tandem affinity purification (140), protein arrays (141), protein fragment complementation (142) and nuclear magnetic resonance (NMR) spectroscopy $(136,143)$. In vivo methods 


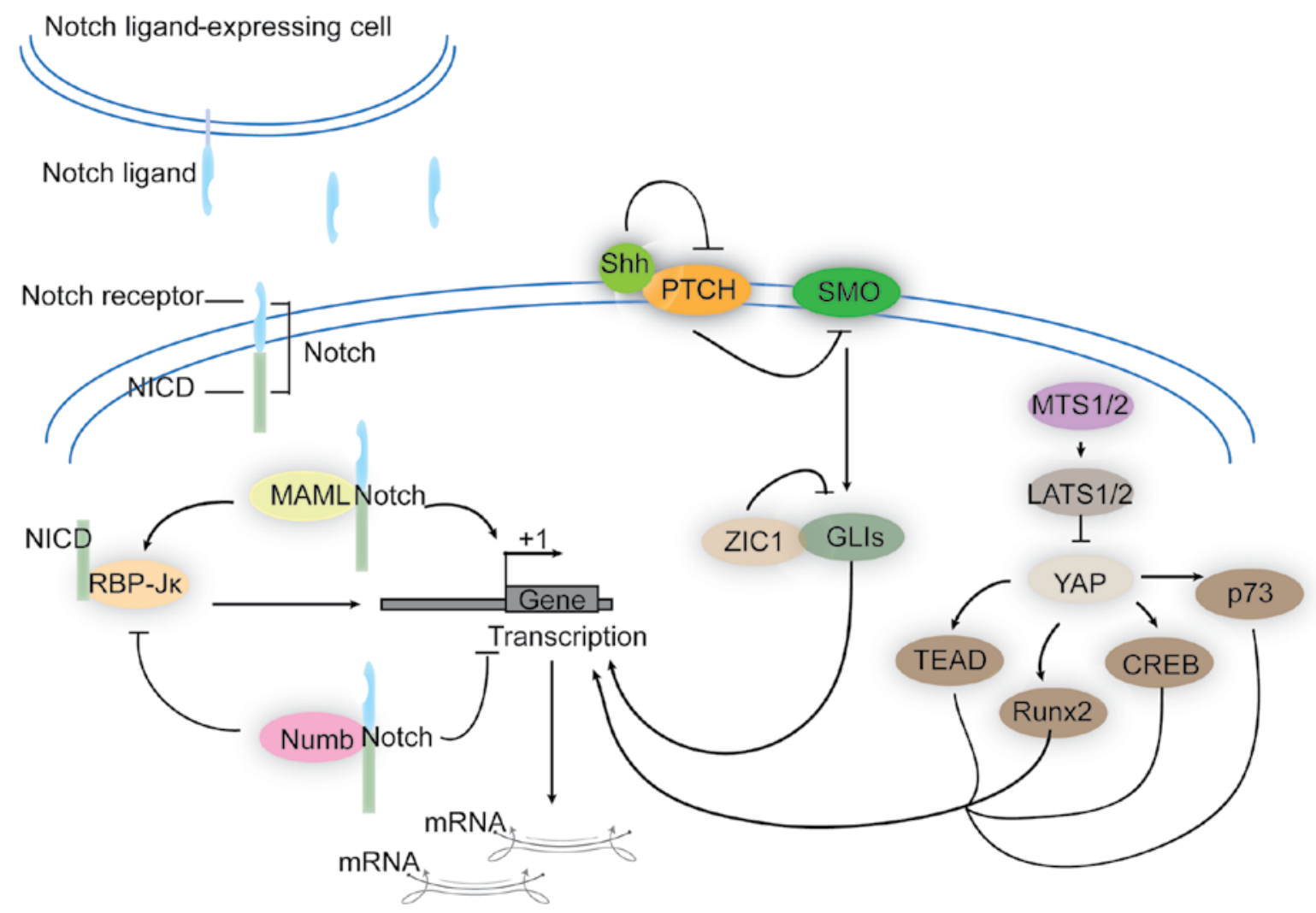

Figure 2. PPIs in Notch, Hedgehog and Hippo/YAP pathway during tumor formation. Direct PPIs in Notch, hedgehog and Hippo/YAP signaling pathway involved in liver cancer are shown.

for detecting PPIs include yeast two-hybrid (Y2H) (144) and synthetic lethality (145). As for in silico prediction, there are sequence-based approaches (146), structure-based approaches (147), gene fusion analysis (148), chromosome proximity (149), in silico two-hybrid (150), phylogenetic tree (151), mirror tree (152) and gene ontology (153).

Massive identification of PPIs generates numerous interactions, which are collected together in PPI databases that are continuously updated to provide complete interactions. The database of interacting proteins (DIP) is the first PPI database globally (154). The number of public PPI databases has increased rapidly. For example, the Biological General Repository for Interaction Datasets (BioGRID: http://thebiogrid.org) is an open access database that houses genetic and protein interactions curated from the primary biomedical literature for all major model organisms and human. BioGRID contains 749,912 interactions as drawn from 43,149 publications describing studies in $>30$ model organisms (155). Another example is the Protein Interaction Network Analysis (PINA) platform, which is for protein interaction network construction, filtering, analysis, visualization and management. It integrates PPI data from six public curated databases and constructs a complete, non-redundant protein interaction dataset for six model organisms. PINA also provides a variety of built-in tools to filter and analyze the network to gain insight into the network (156).

Public databases such as HitPredict (http://hintdb.hgc.jp/ htp/) (157), IntAct (http://www.ebi.ac.uk/intact/) (158), Agile Protein Interaction DataAnalyzer (APID) (http://bioinfow. dep.usal.es/apid/index.htm) (159) and MINT (http://mint. bio.uniroma2.it/mint/) (160) include the PPIs data and are continuously updated.

\section{Conclusion}

In summary, signal transduction plays a fundamental role in many biological processes as well as in many diseases. In liver cancer, many signaling pathways including PI3K/AKT, Ras/Mek/ERK, IKK/NF- $\kappa$ B, Wnt/ $\beta$-catenin, TGF- $\beta$, Notch, hedgehog and Hippo/YAP are shown to be dysregulated. The majority of these signaling pathways have PPIs with PI3K/AKT signaling pathways. Identification of PPI is the crucial step involved in identifying the signal transduction pathways. Signals propagation to inside and/or along the interior of cells depends on PPIs between the various signaling molecules. Numerous properties of PPI such as allosteric sites and hotspots, have been incorporated into drug-design strategies. The relevance of PPI as putative therapeutic targets for the development of new treatments is particularly evident in liver cancer. The investigation of PPIs in signaling pathways may provide knowledge on biochemical cascades and disease pathogenesis, and new therapeutic targets in liver cancer.

\section{Acknowledgements}

The present study was supported by the Yangfan Project of the Shanghai Committee of Science and Technology (14YF1412300), the Outstanding Youth Training Program of Tongji University (1501219080) and the Shanghai Tenth People's Hospital Climbing Training Program (04.01.13024). 


\section{References}

1. Jemal A, Bray F, Center MM, Ferlay J, Ward E and Forman D: Global cancer statistics. CA Cancer J Clin 61: 69-90, 2011.

2. Arzumanyan A, Reis HM and Feitelson MA: Pathogenic mechanisms in HBV- and HCV-associated hepatocellular carcinoma. Nat Rev Cancer 13: 123-135, 2013.

3. Squires RH, Ng V, Romero R, Ekong U, Hardikar W, Emre S and Mazariegos GV: Evaluation of the pediatric patient for liver transplantation: 2014 practice guideline by the American Association for the Study of Liver Diseases, American Society of Transplantation and the North American Society for Pediatric Gastroenterology, Hepatology, and Nutrition. J Pediatr Gastroenterol Nutr 59: 112-131, 2014.

4. Lo CM: Liver transplantation in 2012: Transplantation for liver cancer - more with better results. Nat Rev Gastroenterol Hepatol 10: 74-76, 2013.

5. Lie PP, Cheng CY and Mruk DD: Signalling pathways regulating the blood-testis barrier. Int J Biochem Cell Biol 45: 621-625, 2013.

6. Kandori H, Sudo Y and Furutani Y: Protein-protein interaction changes in an archaeal light-signal transduction. J Biomed Biotechnol 2010: 424760, 2010.

7. Chakraborty C, Doss C GP, Chen L and Zhu H: Evaluating protein-protein interaction (PPI) networks for diseases pathway, target discovery, and drug-design using 'in silico pharmacology' Curr Protein Pept Sci 15: 561-571, 2014.

8. Pal I and Mandal M: PI3K and Akt as molecular targets for cancer therapy: Current clinical outcomes. Acta Pharmacol Sin 33: 1441-1458, 2012.

9. Danielsen SA, Eide PW, Nesbakken A, Guren T, Leithe E and Lothe RA: Portrait of the PI3K/AKT pathway in colorectal cancer. Biochim Biophys Acta 1855: 104-121, 2015.

10. Chang F, Lee JT, Navolanic PM, Steelman LS, Shelton JG, Blalock WL, Franklin RA and McCubrey JA: Involvement of PI3K/Akt pathway in cell cycle progression, apoptosis, and neoplastic transformation: A target for cancer chemotherapy. Leukemia 17: 590-603, 2003

11. Sabine VS, Crozier C, Brookes CL, Drake C, Piper T, van de Velde CJ, Hasenburg A, Kieback DG, Markopoulos C, Dirix L, et al: Mutational analysis of PI3K/AKT signaling pathway in tamoxifen exemestane adjuvant multinational pathology study. J Clin Oncol 32: 2951-2958, 2014

12. Safdari Y, Khalili M, Ebrahimzadeh MA, Yazdani Y and Farajnia S: Natural inhibitors of PI3K/AKT signaling in breast cancer: Emphasis on newly-discovered molecular mechanisms of action. Pharmacol Res 93: 1-10, 2014.

13. Matsuoka $\mathrm{T}$ and Yashiro M: The role of PI3K/Akt/mTOR signaling in gastric carcinoma. Cancers (Basel) 6: 1441-1463, 2014

14. Sarbassov DD, Guertin DA, Ali SM and Sabatini DM: Phosphorylation and regulation of Akt/PKB by the rictor-mTOR complex. Science 307: 1098-1101, 2005.

15. Jacinto E, Facchinetti V, Liu D, Soto N, Wei S, Jung SY, Huang Q, Qin J and Su B: SIN1/MIP1 maintains rictor-mTOR complex integrity and regulates Akt phosphorylation and substrate specificity. Cell 127: 125-137, 2006

16. Manning BD and Cantley LC: AKT/PKB signaling: Navigating downstream. Cell 129: 1261-1274, 2007.

17. Ozes ON, Mayo LD, Gustin JA,Pfeffer SR, Pfeffer LM and Donner DB: NF-kappaB activation by tumour necrosis factor requires the Akt serine-threonine kinase. Nature 401: 82-85, 1999.

18. Lu Y and Wahl LM: Production of matrix metalloproteinase-9 by activated human monocytes involves a phosphatidylinositol-3 kinase/Akt/IKKalpha/NF-kappaB pathway. J Leukoc Biol 78: 259-265, 2005

19. Vandermoere F, El Yazidi-Belkoura I, Adriaenssens E, Lemoine J and Hondermarck $\mathrm{H}$ : The antiapoptotic effect of fibroblast growth factor-2 is mediated through nuclear factor-kappaB activation induced via interaction between Akt and IkappaB kinase-beta in breast cancer cells. Oncogene 24: 5482-5491, 2005.

20. Tu CC, Cheng LH, Hsu HH, Chen LM, Lin YM, Chen MC, Lee NH, Tsai FJ, Huang CY and Wu WJ: Activation of snail and EMT-like signaling via the IKK $\alpha \beta / N F-\kappa B$ pathway in Apicidinresistant HA22T hepatocellular carcinoma cells. Chin J Physio 56: 326-333, 2013.

21. Noh JH, Bae HJ, Eun JW, Shen Q, Park SJ, Kim HS, Nam B, Shin WC, Lee EK, Lee K, et al: HDAC2 provides a critical support to malignant progression of hepatocellular carcinoma through feedback control of mTORC1 and AKT. Cancer Res 74: $1728-1738,2014$
22. Zhang R, Cao X, Wang C, Hou L, Nie J, Zhou M and Feng Y: An antitumor peptide from Musca domestica pupae (MATP) induces apoptosis in HepG2 cells through a JNK-mediated and Akt-mediated NF- $\kappa B$ pathway. Anticancer Drugs 23: 827-835, 2012.

23. Yuan Z, Kim D, Shu S, Wu J, Guo J, Xiao L, Kaneko S, Coppola D and Cheng JQ: Phosphoinositide 3-kinase/Akt inhibits MST1mediated pro-apoptotic signaling through phosphorylation of threonine 120. J Biol Chem 285: 3815-3824, 2010.

24. Wang CY, Tsai AC, Peng CY, Chang YL, Lee KH, Teng CM and Pan SL: Dehydrocostuslactone suppresses angiogenesis in vitro and in vivo through inhibition of Akt/GSK-3 $\beta$ and mTOR signaling pathways. PLoS One 7: e31195, 2012.

25. Su Y, Fu C, Ishikawa S, Stella A, Kojima M, Shitoh K, Schreiber EM, Day BW and Liu B: APC is essential for targeting phosphorylated beta-catenin to the SCFbeta-TrCP ubiquitin ligase. Mol Cell 32: 652-661, 2008.

26. Bauer L, Langer R, Becker K, Hapfelmeier A, Ott K, Novotny A, Höfler $\mathrm{H}$ and Keller G: Expression profiling of stem cell-related genes in neoadjuvant-treated gastric cancer: A NOTCH2, GSK3B and $\beta$-catenin gene signature predicts survival. PLoS One 7: e44566, 2012.

27. Hsieh $\mathrm{CH}$, Cheng LH, Hsu HH, Ho TJ, Tu CC, Lin YM, Chen MC, Tsai FJ, Hsieh YL and Huang CY: Apicidin-resistant HA22T hepatocellular carcinoma cells strongly activated the Wnt/ $\beta$-catenin signaling pathway and MMP-2 expression via the IGF-IR/PI3K/Akt signaling pathway enhancing cell metastatic effect. Biosci Biotechnol Biochem 77: 2397-2404, 2013

28. Mavila N, James D, Utley S, Cu N, Coblens O, Mak K, Rountree CB, Kahn M and Wang KS: Fibroblast growth factor receptor-mediated activation of AKT- $\beta$-catenin-CBP pathway regulates survival and proliferation of murine hepatoblasts and hepatic tumor initiating stem cells. PLoS One 7: e50401, 2012.

29. Liu L, Dai Y, Chen J, Zeng T, Li Y, Chen L, Zhu YH, Li J, Li Y, Ma S, et al: Maelstrom promotes hepatocellular carcinoma metastasis by inducing epithelial-mesenchymal transition by way of Akt/GSK-3 $\beta /$ Snail signaling. Hepatology 59: 531-543, 2014.

30. Gotoh J, Obata M, Yoshie M, Kasai S and Ogawa K: Cyclin D1 over-expression correlates with beta-catenin activation, but not with H-ras mutations, and phosphorylation of Akt, GSK3 beta and ERK1/2 in mouse hepatic carcinogenesis. Carcinogenesis 24: 435-442, 2003.

31. Woo JK, Choi Y, Oh SH, Jeong JH, Choi DH, Seo HS and Kim CW: Mucin 1 enhances the tumor angiogenic response by activation of the AKT signaling pathway. Oncogene 31: 2187-2198, 2012

32. Niault TS and Baccarini M: Targets of Raf in tumorigenesis. Carcinogenesis 31: 1165-1174, 2010.

33. Nikolaev SI, Rimoldi D, Iseli C, Valsesia A, Robyr D, Gehrig C, Harshman K, Guipponi M, Bukach O, Zoete V, et al: Exome sequencing identifies recurrent somatic MAP2K1 and MAP2K2 mutations in melanoma. Nat Genet 44: 133-139, 2012.

34. Barthwal MK, Sathyanarayana P, Kundu CN, Rana B, Pradeep A Sharma C, Woodgett JR and Rana A: Negative regulation of mixed lineage kinase 3 by protein kinase B/AKT leads to cell survival. J Biol Chem 278: 3897-3902, 2003.

35. Kim AH, Khursigara G, Sun X, Franke TF and Chao MV: Akt phosphorylates and negatively regulates apoptosis signalregulating kinase 1. Mol Cell Biol 21: 893-901, 2001.

36. Zimmermann $S$ and Moelling K: Phosphorylation and regulation of Raf by Akt (protein kinase B). Science 286: 1741-1744, 1999.

37. Kane LP, Mollenauer MN, Xu Z, Turck CW and Weiss A: Akt-dependent phosphorylation specifically regulates Cot induction of NF-kappa B-dependent transcription. Mol Cell Biol 22: 5962-5974, 2002 .

38. Park HS, Kim MS, Huh SH, Park J, Chung J, Kang SS and Choi EJ: Akt (protein kinase B) negatively regulates SEK1 by means of protein phosphorylation. J Biol Chem 277: 2573-2578, 2002.

39. Rane MJ, Coxon PY, Powell DW, Webster R, Klein JB, Pierce W, Ping P and McLeish KR: p38 Kinase-dependent MAPKAPK-2 activation functions as 3-phosphoinositide-dependent kinase-2 for Akt in human neutrophils. J Biol Chem 276: 3517-3523, 2001

40. Nishitani Y and Matsumoto H: Ethanol rapidly causes activation of JNK associated with ER stress under inhibition of ADH. FEBS Lett 580: 9-14, 2006.

41. Kim JW, Lee JE, Kim MJ, Cho EG, Cho SG and Choi EJ: Glycogen synthase kinase 3 beta is a natural activator of mitogenactivated protein kinase/extracellular signal-regulated kinase kinase kinase 1 (MEKK1). J Biol Chem 278: 13995-14001, 2003. 
42. Zhou BP, Liao Y, Xia W, Zou Y, Spohn B and Hung MC: HER-2 neu induces p53 ubiquitination via Akt-mediated MDM2 phosphorylation. Nat Cell Biol 3: 973-982, 2001.

43. Ashcroft M, Ludwig RL, Woods DB, Copeland TD, Weber HO, MacRae EJ and Vousden KH: Phosphorylation of HDM2 by Akt. Oncogene 21: 1955-1962, 2002.

44. Fu Z, Ren L, Wei H, Lv J, Che X, Zhu Z, Jia J, Wang L, Lin G, Lu R, et al: Effects of Tyroserleutide on phosphatidylinositol 3'-kinase/AKT pathway in human hepatocellular carcinoma cell. J Drug Target 22: 146-155, 2014.

45. Wang C, Qi R, Li N, Wang Z, An H, Zhang Q, Yu Y and Cao X: Notch1 signaling sensitizes tumor necrosis factor-related apoptosis-inducing ligand-induced apoptosis in human hepatocellular carcinoma cells by inhibiting Akt/Hdm2-mediated p53 degradation and up-regulating p53-dependent DR5 expression. J Biol Chem 284: 16183-16190, 2009.

46. Song J, Park S, Kim M and Shin I: Down-regulation of Notchdependent transcription by Akt in vitro. FEBS Lett 582: 1693-1699, 2008.

47. Xu L, Zhu Y, Xu J, Wu K, Li J, Xu W, Liu H, Wang S, Yin H, Chen L, et al: Notch1 activation promotes renal cell carcinoma growth via PI3K/Akt signaling. Cancer Sci 103: 1253-1258, 2012

48. Huntzicker EG, Hötzel K, Choy L, Che L, Ross J, Pau G, Sharma N, Siebel CW, Chen X and French DM: Differential effects of targeting Notch receptors in a mouse model of liver cancer. Hepatology 61: 942-952, 2014.

49. Brana I, Berger R, Golan T, Haluska P, Edenfield J, Fiorica J, Stephenson J, Martin LP, Westin S, Hanjani P, et al: A parallelarm phase I trial of the humanised anti-IGF-1R antibody dalotuzumab in combination with the AKT inhibitor MK-2206, the mTOR inhibitor ridaforolimus, or the NOTCH inhibitor MK-0752, in patients with advanced solid tumours. Br J Cancer 111: 1932-1944, 2014.

50. Fielhaber JA, Han YS, Tan J, Xing S, Biggs CM, Joung KB and Kristof AS: Inactivation of mammalian target of rapamycin increases STAT1 nuclear content and transcriptional activity in alpha4- and protein phosphatase 2A-dependent fashion. J Biol Chem 284: 24341-24353, 2009.

51. Yang F, Zhang W, Li D and Zhan Q: Gadd45a suppresses tumor angiogenesis via inhibition of the mTOR/STAT3 protein pathway. J Biol Chem 288: 6552-6560, 2013.

52. Sekulić A, Hudson CC, Homme JL, Yin P, Otterness DM, Karnitz LM and Abraham RT: A direct linkage between the phosphoinositide 3-kinase-AKT signaling pathway and the mammalian target of rapamycin in mitogen-stimulated and transformed cells. Cancer Res 60: 3504-3513, 2000.

53. Dunlop EA and Tee AR: Mammalian target of rapamycin complex 1: Signalling inputs, substrates and feedback mechanisms. Cell Signal 21: 827-835, 2009.

54. Mamane Y, Petroulakis E, LeBacquer O and Sonenberg $\mathrm{N}$ : mTOR, translation initiation and cancer. Oncogene 25: 6416-6422, 2006

55. Zhou Q, Lui VW and Yeo W: Targeting the PI3K/Akt/mTOR pathway in hepatocellular carcinoma. Future Oncol 7: 1149-1167, 2011.

56. Zhou L, Huang Y, Li J and Wang Z: The mTOR pathway is associated with the poor prognosis of human hepatocellular carcinoma. Med Oncol 27: 255-261, 2010.

57. Nissen NN1, Menon V, Bresee C, Tran TT, Annamalai A, Poordad F, Fair JH, Klein AS, Boland B and Colquhoun SD: Recurrent hepatocellular carcinoma after liver transplant: identifying the high-risk patient. HPB 13: 626-632, 2011.

58. Nakae J, Kitamura T, Kitamura Y, Biggs WH III, Arden KC and Accili D: The forkhead transcription factor Foxol regulates adipocyte differentiation. Dev Cell 4: 119-129, 2003.

59. Hay N: Interplay between FOXO, TOR, and Akt. Biochim Biophys Acta 1813: 1965-1970, 2011.

60. Nakae J, Kitamura T, Silver DL and Accili D: The forkhead transcription factor Foxol (Fkhr) confers insulin sensitivity onto glucose-6-phosphatase expression. J Clin Invest 108: 1359-1367, 2001.

61. Khor TO, Gul YA, Ithnin H and Seow HF: Positive correlation between overexpression of phospho-BAD with phosphorylated Akt at serine 473 but not threonine 308 in colorectal carcinoma. Cancer Lett 210: 139-150, 2004.

62. Huang CS, Lee YR, Chen CS, Tu SH, Wang YJ, Lee CH, Chen LC, Chang HW, Chang CH, Chih-Ming S, et al: Long-term ethanol exposure causes human liver cancer cells to become resistant to mitomycin $\mathrm{C}$ treatment through the inactivation of bad-mediated apoptosis. Mol Carcinog 49: 728-738, 2010.
63. Carrano AC and Pagano M: Role of the F-box protein Skp2 in adhesion-dependent cell cycle progression. J Cell Biol 153: 1381-1390, 2001

64. Lin HK, Wang G, Chen Z, Teruya-Feldstein J, Liu Y, Chan CH, Yang WL, Erdjument-Bromage H, Nakayama KI, Nimer S, et al: Phosphorylation-dependent regulation of cytosolic localization and oncogenic function of Skp2 by Akt/PKB. Nat Cell Biol 11: 420-432, 2009.

65. Ho C, Wang C, Mattu S, Destefanis G, Ladu S, Delogu S, Armbruster J, Fan L, Lee SA, Jiang L, et al: AKT (v-akt murine thymoma viral oncogene homolog 1) and N-Ras (neuroblastoma ras viral oncogene homolog) coactivation in the mouse liver promotes rapid carcinogenesis by way of mTOR (mammalian target of rapamycin complex 1), FOXM1 (forkhead box M1)/ SKP2, and c-Myc pathways. Hepatology 55: 833-845, 2012.

66. Lu NZ, Wardell SE, Burnstein KL, Defranco D, Fuller PJ, Giguere V, Hochberg RB, McKay L, Renoir JM, Weigel NL, et al: International Union of Pharmacology. LXV. The pharmacology and classification of the nuclear receptor superfamily: Glucocorticoid, mineralocorticoid, progesterone, and androgen receptors. Pharmacol Rev 58: 782-797, 2006.

67. Lin HK, Yeh S, Kang HY and Chang C: Akt suppresses androgen-induced apoptosis by phosphorylating and inhibiting androgen receptor. Proc Natl Acad Sci USA 98: 7200-7205, 2001.

68. Ma WL, Jeng LB, Lai HC, Liao PY and Chang C: Androgen receptor enhances cell adhesion and decreases cell migration via modulating $\beta 1$-integrin-AKT signaling in hepatocellular carcinoma cells. Cancer Lett 351: 64-71, 2014.

69. Nie H, Cao Q, Zhu L, Gong Y, Gu J and He Z: Acetylcholine acts on androgen receptor to promote the migration and invasion but inhibit the apoptosis of human hepatocarcinoma. PLoS One 8: e61678, 2013.

70. Hong X, Song R, Song H, Zheng T, Wang J, Liang Y, Qi S, Lu Z, Song X, Jiang H, et al: PTEN antagonises Tcll/hnRNPKmediated G6PD pre-mRNA splicing which contributes to hepatocarcinogenesis. Gut 63: 1635-1647, 2014.

71. Wang XQ, Ongkeko WM, Chen L, Yang ZF, Lu P, Chen KK, Lopez JP, Poon RT and Fan ST: Octamer 4 (Oct4) mediates chemotherapeutic drug resistance in liver cancer cells through a potential Oct4-AKT-ATP-binding cassette G2 pathway. Hepatology 52: 528-539, 2010.

72. Vasan N, Yelensky R, Wang K, Moulder S, Dzimitrowicz H, Avritscher R, Wang B, Wu Y, Cronin MT, Palmer G, et al: A targeted next-generation sequencing assay detects a high frequency of therapeutically targetable alterations in primary and metastatic breast cancers: Implications for clinical practice. Oncologist 19: 453-458, 2014.

73. Kittaka N, Takemasa I, Takeda Y, Marubashi S, Nagano H, Umeshita K, Dono K, Matsubara K, Matsuura N and Monden M: Molecular mapping of human hepatocellular carcinoma provides deeper biological insight from genomic data. Eur J Cancer 44: 885-897, 2008.

74. Chan J, Ko FC, Yeung YS, Ng IO and Yam JW: Integrin-linked kinase overexpression and its oncogenic role in promoting tumorigenicity of hepatocellular carcinoma. PLoS One 6: e16984, 2011.

75. Peroukides S, Bravou V, Varakis J, Alexopoulos A, Kalofonos H and Papadaki H: ILK overexpression in human hepatocellular carcinoma and liver cirrhosis correlates with activation of Akt. Oncol Rep 20: 1337-1344, 2008.

76. Cui Y, Wu W, Zhou Y, Xie Q, Liu T, Jin J and Liu K: HSP27 expression levels are associated with the sensitivity of hepatocellular carcinoma cells to 17-allylamino-17-demethoxygeldanamycin. Future Oncol 9: 411-418, 2013.

77. Nam SY, Seo HH, Park HS, An S, Kim JY, Yang KH, Kim CS, Jeong M and Jin YW: Phosphorylation of CLK2 at serine 34 and threonine 127 by AKT controls cell survival after ionizing radiation. J Biol Chem 285: 31157-31163, 2010.

78. Villagrasa P, Díaz VM, Viñas-Castells R, Peiró S, Del VallePérez B, Dave N, Rodríguez-Asiain A, Casal JI, Lizcano JM, Duñach M, et al: Akt2 interacts with Snaill in the E-cadherin promoter. Oncogene 31: 4022-4033, 2012.

79. Thirumurthi U, Shen J, Xia W, LaBaff AM, Wei Y, Li CW, Chang WC, Chen CH, Lin HK, Yu D, et al: MDM2-mediated degradation of SIRT6 phosphorylated by AKT1 promotes tumorigenesis and trastuzumab resistance in breast cancer. Sci Signal 7: ra71, 2014.

80. Zhao R, Yang HY, Shin J, Phan L, Fang L, Che TF, Su CH, Yeung SC and Lee MH: CDK inhibitor $\mathrm{p} 57^{\mathrm{Kip} 2}$ is downregulated by Akt during HER2-mediated tumorigenicity. Cell Cycle 12: 935-943, 2013. 
81. Zeng L, Bai M, Mittal AK, El-Jouni W, Zhou J, Cohen DM, Zhou MI and Cohen HT: Candidate tumor suppressor and pVHL partner Jade-1 binds and inhibits AKT in renal cell carcinoma. Cancer Res 73: 5371-5380, 2013.

82. Yang WL, Jin G, Li CF, Jeong YS, Moten A, Xu D, Feng Z, Chen W, Cai Z, Darnay B, et al: Cycles of ubiquitination and deubiquitination critically regulate growth factor-mediated activation of Akt signaling. Sci Signal 6: ra3, 2013.

83. Thoreen CC, Kang SA, Chang JW, Liu Q, Zhang J, Gao Y, Reichling LJ, Sim T, Sabatini DM and Gray NS: An ATP-competitive mammalian target of rapamycin inhibitor reveals rapamycin-resistant functions of mTORC1. J Biol Chem 284: 8023-8032, 2009.

84. Yu K, Toral-Barza L, Shi C, Zhang WG, Lucas J, Shor B, Kim J, Verheijen J, Curran K, Malwitz DJ, et al: Biochemical, cellular, and in vivo activity of novel ATP-competitive and selective inhibitors of the mammalian target of rapamycin. Cancer Res 69: 6232-6240, 2009.

85. García-Martínez JM, Moran J, Clarke RG, Gray A, Cosulich SC, Chresta CM and Alessi DR: Ku-0063794 is a specific inhibitor of the mammalian target of rapamycin (mTOR). Biochem J 421: 29-42, 2009

86. Monaco AP: The role of mTOR inhibitors in the management of posttransplant malignancy. Transplantation 87: 157-163, 2009.

87. Menon KV, Hakeem AR and Heaton ND: Meta-analysis: Recurrence and survival following the use of sirolimus in liver transplantation for hepatocellular carcinoma. Aliment Pharmacol Ther 37: 411-419, 2013.

88. Ashworth RE and Wu J: Mammalian target of rapamycin inhibition in hepatocellular carcinoma. World J Hepatol 6: 776-782, 2014.

89. Zhu AX, Abrams TA, Miksad R, Blaszkowsky LS, Meyerhardt JA, Zheng H, Muzikansky A, Clark JW, Kwak EL, Schrag D, et al: Phase $1 / 2$ study of everolimus in advanced hepatocellular carcinoma. Cancer 117: 5094-5102, 2011.

90. Chen L, Shiah HS, Chen CY, Lin YJ, Lin PW, Su WC and Chang JY: Randomized, phase I, and pharmacokinetic (PK) study of RAD001, and mTOR inhibitor, in patients (pts) with advanced hepatocellular carcinoma (HCC). J Clin Oncol 27: $4587,2009$.

91. Zhao B, Ma Y, Xu Z, Wang J, Wang F, Wang D, Pan S, Wu Y, Pan H, Xu D, et al: Hydroxytyrosol, a natural molecule from olive oil, suppresses the growth of human hepatocellular carcinoma cells via inactivating AKT and nuclear factor-kappa B pathways. Cancer Lett 347: 79-87, 2014.

92. Omar HA: Arafa el SA, Maghrabi IA and Weng JR: Sensitization of hepatocellular carcinoma cells to Apo2L/TRAIL by a novel Akt/NF-kappaB signalling inhibitor. Basic Clin Pharmacol Toxicol 114: 464-471, 2014

93. Lee SJ, Hwang JW, Yim H, Yim HJ, Woo SU, Suh SJ, Hyun JJ, Jung SW, Koo JS, Kim JH, et al: Synergistic effect of simvastatin plus NS398 on inhibition of proliferation and survival in hepatocellular carcinoma cell line. J Gastroenterol Hepatol 29: 1299-1307, 2014

94. Zheng YH, Yin LH, Grahn TH, Ye AF, Zhao YR and Zhang QY: Anticancer effects of baicalein on hepatocellular carcinoma cells. Phytother Res 28: 1342-1348, 2014.

95. Chow AK, Ng L, Sing Li H, Cheng CW, Lam CS, Yau TC, Cheng PN, Fan ST, Poon RT and Pang RW: Anti-tumor efficacy of a recombinant human arginase in human hepatocellular carcinoma. Curr Cancer Drug Targets 12: 1233-1243, 2012

96. Yang F, Deng R, Qian XJ, Chang SH, Wu XQ, Qin J, Feng GK, Ding $K$ and Zhu XF: Feedback loops blockade potentiates apoptosis induction and antitumor activity of a novel AKT inhibitor DC120 in human liver cancer. Cell Death Dis 5: e1114, 2014.

97. Vassilev LT, Vu BT, Graves B, Carvajal D, Podlaski F, Filipovic Z, Kong N, Kammlott U, Lukacs C, Klein C, et al: In vivo activation of the p53 pathway by small-molecule antagonists of MDM2. Science 303: 844-848, 2004

98. Li M, Zhang Z, Hill DL, Wang H and Zhang R: Curcumin, a dietary component, has anticancer, chemosensitization, and radiosensitization effects by down-regulating the MDM2 oncogene through the PI3K/mTOR/ETS2 pathway. Cancer Res 67: 1988-1996, 2007.

99. Li M, Li Q, Zhang YH, Tian ZY, Ma HX, Zhao J, Xie SQ and Wang CJ: Antitumor effects and preliminary systemic toxicity of ANISpm in vivo and in vitro. Anticancer Drugs 24: 32-42, 2013.
100. Xie SQ, Zhang YH, Li Q, Xu FH, Miao JW, Zhao J and Wang CJ: 3-Nitro-naphthalimide and nitrogen mustard conjugate NNM-25 induces hepatocellular carcinoma apoptosis via PARP-1/p53 pathway. Apoptosis 17: 725-734, 2012.

101. Tanaka T and Rabbitts TH: Interfering with protein-protein interactions: Potential for cancer therapy. Cell Cycle 7 : 1569-1574, 2008.

102. Artavanis-Tsakonas S, Rand MD and Lake RJ: Notch signaling: Cell fate control and signal integration in development. Science 284: 770-776, 1999.

103. Brou C, Logeat F, Gupta N, Bessia C, LeBail O, Doedens JR, Cumano A, Roux P, Black RA and Israël A: A novel proteolytic cleavage involved in Notch signaling: The role of the disintegrinmetalloprotease TACE. Mol Cell 5: 207-216, 2000.

104. Ayaz F and Osborne BA: Non-canonical notch signaling in cancer and immunity. Front Oncol 4: 345, 2014

105. Wu L, Aster JC, Blacklow SC, Lake R, Artavanis-Tsakonas S and Griffin JD: MAML1, a human homologue of Drosophila mastermind, is a transcriptional co-activator for $\mathrm{NOTCH}$ receptors. Nat Genet 26: 484-489, 2000.

106. Villanueva A, Alsinet C, Yanger K, Hoshida Y, Zong Y, Toffanin S, Rodriguez-Carunchio L, Solé M, Thung S, Stanger BZ, et al: Notch signaling is activated in human hepatocellular carcinoma and induces tumor formation in mice. Gastroenterology 143: 1660-1669.e7, 2012.

107. Liu M, Lee DF, Chen CT, Yen CJ, Li LY, Lee HJ, Chang CJ, Chang WC, Hsu JM, Kuo HP, et al: IKK $\alpha$ activation of NOTCH links tumorigenesis via FOXA2 suppression. Mol Cell 45: $171-184,2012$

108. Nüsslein-Volhard C and Wieschaus E: Mutations affecting segment number and polarity in Drosophila. Nature 287: 795-801, 1980

109. Pepinsky RB, Zeng C, Wen D, Rayhorn P, Baker DP, Williams KP, Bixler SA, Ambrose CM, Garber EA, Miatkowski K, et al: Identification of a palmitic acid-modified form of human Sonic hedgehog. J Biol Chem 273: 14037-14045, 1998.

110. Porter JA, Young KE and Beachy PA: Cholesterol modification of hedgehog signaling proteins in animal development. Science 274: 255-259, 1996.

111. Marigo V, Davey RA, Zuo Y, Cunningham JM and Tabin CJ: Biochemical evidence that patched is the Hedgehog receptor. Nature 384: 176-179, 1996.

112. Stone DM, Hynes M, Armanini M, Swanson TA, Gu Q Johnson RL, Scott MP, Pennica D, Goddard A, Phillips H, et al: The tumour-suppressor gene patched encodes a candidate receptor for Sonic hedgehog. Nature 384: 129-134, 1996.

113. Taipale J, Cooper MK, Maiti T and Beachy PA: Patched acts catalytically to suppress the activity of Smoothened. Nature 418 892-897, 2002

114. Sicklick JK, Li YX, Jayaraman A, Kannangai R, Qi Y, Vivekanandan P, Ludlow JW, Owzar K, Chen W, Torbenson MS, et al: Dysregulation of the Hedgehog pathway in human hepatocarcinogenesis. Carcinogenesis 27: 748-757, 2006.

115. Patil MA, Zhang J, Ho C, Cheung ST, Fan ST and Chen X Hedgehog signaling in human hepatocellular carcinoma. Cancer Biol Ther 5: 111-117, 2006.

116. Zheng X, Zeng W, Gai X, Xu Q, Li C, Liang Z, Tuo H and Liu Q: Role of the Hedgehog pathway in hepatocellular carcinoma (Review). Oncol Rep 30: 2020-2026, 2013.

117. Koyabu Y, Nakata K, Mizugishi K, Aruga J and Mikoshiba K Physical and functional interactions between $\mathrm{Zic}$ and Gli proteins. J Biol Chem 276: 6889-6892, 2001.

118. Wang YY, Jiang JX, Ma H, Han J, Sun ZY, Liu ZM and Xu ZG Role of ZIC1 methylation in hepatocellular carcinoma and its clinical significance. Tumour Biol 35: 7429-7433, 2014

119. Badouel C, Garg A and McNeill H: Herding Hippos: Regulating growth in flies and man. Curr Opin Cell Biol 21: 837-843, 2009

120. Dong J, Feldmann G, Huang J, Wu S, Zhang N, Comerford SA, Gayyed MF, Anders RA, Maitra A and Pan D: Elucidation of a universal size-control mechanism in Drosophila and mammals. Cell 130: 1120-1133, 2007.

121. Zhou D, Conrad C, Xia F, Park JS, Payer B, Yin Y, Lauwers GY, Thasler W, Lee JT, Avruch J, et al: Mst1 and Mst2 maintain hepatocyte quiescence and suppress hepatocellular carcinoma development through inactivation of the Yap1 oncogene. Cancer Cell 16: 425-438, 2009

122. Aragón E, Goerner N, Xi Q, Gomes T, Gao S, Massagué J and Macias MJ: Structural basis for the versatile interactions of Smad7 with regulator WW domains in TGF- $\beta$ pathways. Structure 20: 1726-1736, 2012 
123. Strano S, Munarriz E, Rossi M, Castagnoli L, Shaul Y, Sacchi A, Oren M, Sudol M, Cesareni G and Blandino G: Physical interaction with Yes-associated protein enhances p73 transcriptional activity. J Biol Chem 276: 15164-15173, 2001.

124. Komuro A, Nagai M, Navin NE and Sudol M: WW domaincontaining protein YAP associates with ErbB-4 and acts as a co-transcriptional activator for the carboxyl-terminal fragment of ErbB-4 that translocates to the nucleus. J Biol Chem 278: 33334-33341, 2003

125. Yagi R, Chen LF, Shigesada K, Murakami Y and Ito Y: A WW domain-containing yes-associated protein (YAP) is a novel transcriptional co-activator. EMBO J 18: 2551-2562, 1999.

126. Wang W, Huang J and Chen J: Angiomotin-like proteins associate with and negatively regulate YAP1. J Biol Chem 286: 4364-4370, 2011.

127. Chan SW, Lim CJ, Chong YF, Pobbati AV, Huang C and Hong W: Hippo pathway-independent restriction of TAZ and YAP by angiomotin. J Biol Chem 286: 7018-7026, 2011.

128. Zhao B, Li L, Lu Q, Wang LH, Liu CY, Lei Q and Guan KL: Angiomotin is a novel Hippo pathway component that inhibits YAP oncoprotein. Genes Dev 25: 51-63, 2011.

129. Oka T, Remue E, Meerschaert K, Vanloo B, Boucherie C, Gfeller D, Bader GD, Sidhu SS, Vandekerckhove J, Gettemans J, et al: Functional complexes between YAP2 and ZO-2 are PDZ domain-dependent, and regulate YAP2 nuclear localization and signalling. Biochem J 432: 461-472, 2010.

130. Oka T, Mazack V and Sudol M: Mst2 and Lats kinases regulate apoptotic function of Yes kinase-associated protein (YAP). J Biol Chem 283: 27534-27546, 2008.

131. Zhao B, Wei X, Li W, Udan RS, Yang Q, Kim J, Xie J, Ikenoue T, $\mathrm{Yu} \mathrm{J}, \mathrm{Li} \mathrm{L}$, et al: Inactivation of YAP oncoprotein by the Hippo pathway is involved in cell contact inhibition and tissue growth control. Genes Dev 21: 2747-2761, 2007.

132. Li H, Wolfe A, Septer S, Edwards G, Zhong X, Abdulkarim AB, Ranganathan S and Apte U: Deregulation of Hippo kinase signalling in human hepatic malignancies. Liver Int 32: 38-47, 2012 .

133. Vassilev A, Kaneko KJ, Shu H, Zhao Y and DePamphilis ML: TEAD/TEF transcription factors utilize the activation domain of YAP65, a Src/Yes-associated protein localized in the cytoplasm. Genes Dev 15: 1229-1241, 2001

134. Zhao B, Kim J, Ye X, Lai ZC and Guan KL: Both TEAD-binding and WW domains are required for the growth stimulation and oncogenic transformation activity of yes-associated protein. Cancer Res 69: 1089-1098, 2009.

135. Pobbati AV and Hong W: Emerging roles of TEAD transcription factors and its coactivators in cancers. Cancer Biol Ther 14 390-398, 2013.

136. Rao VS, Srinivas K, Sujini GN and Kumar GN: Protein-protein interaction detection: Methods and analysis. Int J Proteomics 2014: 147648, 2014

137. London AS, Patel K, Quinn L and Lemmerer M: Application of coupled affinity-sizing chromatography for the detection of proteolyzed HSA-tagged proteins. Protein Expr Purif 180: $80-84,2014$.

138. Tong AH, Evangelista M, Parsons AB, Xu H, Bader GD, Pagé N, Robinson M, Raghibizadeh S, Hogue CW, Bussey $\mathrm{H}$, et al Systematic genetic analysis with ordered arrays of yeast deletion mutants. Science 294: 2364-2368, 2001.

139. Song Z, Dong C, Wang L, Chen DE, Bi G, Dai M and Liu J: A novel method for purifying bluetongue virus with high purity by co-immunoprecipitation with agarose protein A. Virol J 7: 126 2010.

140. Rigaut G, Shevchenko A, Rutz B, Wilm M, Mann M and Séraphin B: A generic protein purification method for protein complex characterization and proteome exploration. Nat Biotechnol 17: 1030-1032, 1999.

141. MacBeath G and Schreiber SL: Printing proteins as microarrays for high-throughput function determination. Science 289 : 1760-1763, 2000.

142. Westwick JK and Michnick SW: Protein-fragment complementation assays (PCA) in small GTPase research and drug discovery. Methods Enzymol 407: 388-401, 2006.

143. Palmer AG III: Enzyme dynamics from NMR spectroscopy Acc Chem Res 48: 457-465, 2015.

144. Vidal M and Fields S: The yeast two-hybrid assay: Still finding connections after 25 years. Nat Methods 11: 1203-1206, 2014.

145. Güell O, Sagués F and Serrano MA: Essential plasticity and redundancy of metabolism unveiled by synthetic lethality analysis. PLOS Comput Biol 10: e1003637, 2014.
146. Zhang Y, Jin Q, Wang S and Ren R: Modeling and prediction of peptide drift times in ion mobility spectrometry using sequencebased and structure-based approaches. Comput Biol Med 41: 272-277, 2011

147. Vyas VK, Goel A, Ghate M and Patel P: Ligand and structurebased approaches for the identification of SIRT1 activators. Chem Biol Interact 228: 9-17, 2015.

148. Enright AJ, Iliopoulos I, Kyrpides NC and Ouzounis CA: Protein interaction maps for complete genomes based on gene fusion events. Nature 402: 86-90, 1999.

149. Foster HA, Estrada-Girona G, Themis M, Garimberti E, Hill MA, Bridger JM and Anderson RM: Relative proximity of chromosome territories influences chromosome exchange partners in radiation-induced chromosome rearrangements in primary human bronchial epithelial cells. Mutat Res 756: 66-77, 2013.

150. Pazos F and Valencia A: In silico two-hybrid system for the selection of physically interacting protein pairs. Proteins 47 : 219-227, 2002

151. Whidden C and Matsen FA IV: Quantifying MCMC exploration of phylogenetic tree space. Syst Biol 64: 472-491, 2015.

152. Altman J, Hédl R, Szabó P, Mazůrek P, Riedl V, Müllerová J, Kopecký $\mathrm{M}$ and Doležal J: Tree-rings mirror management legacy: Dramatic response of standard oaks to past coppicing in Central Europe. PLoS One 8: e55770, 2013.

153. Gene Ontology C; Gene Ontology Consortium: Gene Ontology Consortium: Going forward. Nucleic Acids Res 43 (D1): D1049-D1056, 2015.

154. Xenarios I, Salwínski L, Duan XJ, Higney P, Kim SM and Eisenberg D: DIP, the Database of Interacting Proteins: A research tool for studying cellular networks of protein interactions. Nucleic Acids Res 30: 303-305, 2002.

155. Chatr-Aryamontri A, Breitkreutz BJ, Oughtred R, Boucher L, Heinicke S, Chen D, Stark C, Breitkreutz A, Kolas N O'Donnell L, et al: The BioGRID interaction database: 2015 update. Nucleic Acids Res 43 (D1): D470-D478, 2015.

156. Cowley MJ, Pinese M, Kassahn KS, Waddell N, Pearson JV, Grimmond SM, Biankin AV, Hautaniemi S and Wu J: PINA v2.0: Mining interactome modules. Nucleic Acids Res 40 (D1): D862-D865, 2012.

157. Patil A, Nakai K and Nakamura H: HitPredict: A database of quality assessed protein-protein interactions in nine species. Nucleic Acids Res 39 (Database): D744-D749, 2011.

158. Hermjakob H, Montecchi-Palazzi L, Lewington C, Mudali S, Kerrien S, Orchard S, Vingron M, Roechert B, Roepstorff P, Valencia A, et al: IntAct: An open source molecular interaction database. Nucleic Acids Res 32: D452-D455, 2004.

159. Prieto C and De Las Rivas J: APID: Agile Protein Interaction DataAnalyzer. Nucleic Acids Res 34 (Web Server): W298-W302, 2006.

160. Licata L, Briganti L, Peluso D, Perfetto L, Iannuccelli M, Galeota E, Sacco F, Palma A, Nardozza AP, Santonico E, et al: MINT, the molecular interaction database: 2012 update. Nucleic Acids Res 40 (D1): D857-D861, 2012.

161. Song JJ and Lee YJ: Dissociation of Akt1 from its negative regulator JIP1 is mediated through the ASK1-MEK-JNK signal transduction pathway during metabolic oxidative stress: A negative feedback loop. J Cell Biol 170: 61-72, 2005.

162. Kim J, Kang D, Sun BK, Kim JH and Song JJ: TRAIL/MEKK4/ p38/HSP27/Akt survival network is biphasically modulated by the Src/CIN85/c-Cbl complex. Cell Signal 25: 372-379, 2013.

163. Deregibus MC, Cantaluppi V, Doublier S, Brizzi MF, Deambrosis I, Albini A and Camussi G: HIV-1-Tat protein activates phosphatidylinositol 3-kinase/AKT-dependent survival pathways in Kaposi's sarcoma cells. J Biol Chem 277: 25195-25202, 2002

164. Polzien L, Baljuls A, Rennefahrt UE, Fischer A, Schmitz W, Zahedi RP, Sickmann A, Metz R, Albert S, Benz R, et al: Identification of novel in vivo phosphorylation sites of the human proapoptotic protein BAD: Pore-forming activity of BAD is regulated by phosphorylation. J Biol Chem 284: 28004-28020, 2009.

165. Xiang T, Ohashi A, Huang Y, Pandita TK, Ludwig T, Powell SN and Yang Q: Negative regulation of AKT activation by BRCA1. Cancer Res 68: 10040-10044, 2008.

166. Xiang T, Jia Y, Sherris D, Li S, Wang H, Lu D and Yang Q: Targeting the Akt/mTOR pathway in Brcal-deficient cancers. Oncogene 30: 2443-2450, 2011.

167. Du K and Montminy M: CREB is a regulatory target for the protein kinase Akt/PKB. J Biol Chem 273: 32377-32379, 1998. 
168. Matsuzaki H, Daitoku H, Hatta M, Aoyama H, Yoshimochi K and Fukamizu A: Acetylation of Foxol alters its DNA-binding ability and sensitivity to phosphorylation. Proc Natl Acad Sci USA 102: 11278-11283, 2005

169. Brent MM, Anand R and Marmorstein R: Structural basis for DNA recognition by FoxO1 and its regulation by posttranslational modification. Structure 16: 1407-1416, 2008.

170. Biggs WH III, Meisenhelder J, Hunter T, Cavenee WK and Arden KC: Protein kinase B/Akt-mediated phosphorylation promotes nuclear exclusion of the winged helix transcription factor FKHR1. Proc Natl Acad Sci USA 96: 7421-7426, 1999.

171. Yang H, Zhao R, Yang HY and Lee MH: Constitutively active FOXO4 inhibits Akt activity, regulates p27 Kip1 stability, and suppresses HER2-mediated tumorigenicity. Oncogene 24 $1924-1935,2005$

172. Matsuzaki H, Ichino A, Hayashi T, Yamamoto T and Kikkawa U: Regulation of intracellular localization and transcriptional activity of FOXO4 by protein kinase $\mathrm{B}$ through phosphorylation at the motif sites conserved among the FOXO family. J Biochem 138: 485-491, 2005.

173. Zhu QS, Rosenblatt K, Huang KL, Lahat G, Brobey R, Bolshakov S, Nguyen T, Ding Z, Belousov R, Bill K, et al Vimentin is a novel AKT1 target mediating motility and invasion. Oncogene 30: 457-470, 2011.

174. Drendall CI, Pham QH and Dietze EC: Purification and characterization of recombinant $\mathrm{CH} 3$ domain fragment of the CREB-binding protein. Protein Expr Purif 70: 196-205, 2010.

175. Connor MK, Azmi PB, Subramaniam V, Li H and Seth A: Molecular characterization of ring finger protein 11. Mol Cancer Res 3: 453-461, 2005.

176. Yang WL, Wang J, Chan CH, Lee SW, Campos AD, Lamothe B, Hur L, Grabiner BC, Lin X, Darnay BG, et al: The E3 ligase TRAF6 regulates Akt ubiquitination and activation. Science 325: 1134-1138, 2009.

177. Hartman AD, Wilson-Weekes A, Suvannasankha A, Burgess GS, Phillips CA, Hincher KJ, Cripe LD and Boswell HS: Constitutive c-jun N-terminal kinase activity in acute myeloid leukemia derives from Flt 3 and affects survival and proliferation. Exp Hematol 34: 1360-1376, 2006.

178. Kim CK, Lee SB, Nguyen TL, Lee KH, Um SH, Kim J and Ahn JY: Long isoform of ErbB3 binding protein, p48, mediates protein kinase B/Akt-dependent HDM2 stabilization and nuclear localization. Exp Cell Res 318: 136-143, 2012.

179. Deep G, Oberlies NH, Kroll DJ and Agarwal R: Isosilybin $\mathrm{B}$ causes androgen receptor degradation in human prostate carcinoma cells via PI3K-Akt-Mdm2-mediated pathway. Oncogene 27: 3986-3998, 2008.

180. Milne D, Kampanis P, Nicol S, Dias S, Campbell DG, Fuller-Pace F and Meek D: A novel site of AKT-mediated phosphorylation in the human MDM2 onco-protein. FEBS Lett 577: 270-276, 2004.

181. Facchinetti V, Ouyang W, Wei H, Soto N, Lazorchak A, Gould C, Lowry C, Newton AC, Mao Y, Miao RQ, et al: The mammalian target of rapamycin complex 2 controls folding and stability of Akt and protein kinase C. EMBO J 27: 1932-1943, 2008.
182. Oh WJ, Wu CC, Kim SJ, Facchinetti V, Julien LA, Finlan M, Roux PP, Su B and Jacinto E: mTORC2 can associate with ribosomes to promote cotranslational phosphorylation and stability of nascent Akt polypeptide. EMBO J 29: 3939-3951, 2010.

183. Glidden EJ, Gray LG, Vemuru S, Li D, Harris TE and Mayo MW: Multiple site acetylation of Rictor stimulates mammalian target of rapamycin complex 2 (mTORC2)-dependent phosphorylation of Akt protein. J Biol Chem 287: 581-588, 2012.

184. Fan CD, Lum MA, Xu C, Black JD and Wang X: Ubiquitindependent regulation of phospho-AKT dynamics by the ubiquitin E3 ligase, NEDD4-1, in the insulin-like growth factor-1 response. J Biol Chem 288: 1674-1684, 2013.

185. Persaud A, Alberts P, Amsen EM, Xiong X, Wasmuth J, Saadon Z, Fladd C, Parkinson J and Rotin D: Comparison of substrate specificity of the ubiquitin ligases Nedd4 and Nedd4-2 using proteome arrays. Mol Syst Biol 5: 333, 2009.

186. Mistafa O, Ghalali A, Kadekar S, Högberg J and Stenius U: Purinergic receptor-mediated rapid depletion of nuclear phosphorylated Akt depends on pleckstrin homology domain leucine-rich repeat phosphatase, calcineurin, protein phosphatase 2A, and PTEN phosphatases. J Biol Chem 285: 27900-27910, 2010.

187. Woods NT, Mesquita RD, Sweet M, Carvalho MA, Li X, Liu Y, Nguyen H, Thomas CE, Iversen ES Jr, Marsillac S, et al: Charting the landscape of tandem BRCT domain-mediated protein interactions. Sci Signal 5: rs6, 2012.

188. Sarbassov DD, Ali SM, Sengupta S, Sheen JH, Hsu PP, Bagley AF, Markhard AL and Sabatini DM: Prolonged rapamycin treatment inhibits mTORC2 assembly and Akt/PKB. Mol Cell 22: 159-168, 2006.

189. Ikenoue T, Inoki K, Yang Q, Zhou X and Guan KL: Essential function of TORC2 in PKC and Akt turn motif phosphorylation, maturation and signalling. EMBO J 27: 1919-1931, 2008.

190. Chen CH, Shaikenov T, Peterson TR, Aimbetov R, Bissenbaev AK, Lee SW, Wu J, Lin HK and Sarbassov D: ER stress inhibits mTORC2 and Akt signaling through GSK-3 $\beta$ mediated phosphorylation of rictor. Sci Signal 4: ra10, 2011.

191. Sundaresan NR, Pillai VB, Wolfgeher D, Samant S, Vasudevan P, Parekh V, Raghuraman H, Cunningham JM, Gupta M and Gupta MP: The deacetylase SIRT1 promotes membrane localization and activation of Akt and PDK1 during tumorigenesis and cardiac hypertrophy. Sci Signal 4: ra46, 2011.

192. Gao D, Inuzuka H, Tseng A, Chin RY, Toker A and Wei W: Phosphorylation by Aktl promotes cytoplasmic localization of Skp2 and impairs APCCdh1-mediated Skp2 destruction. Nat Cell Biol 11: 397-408, 2009.

193. Romano D, Matallanas D, Weitsman G, Preisinger C, Ng T and Kolch W: Proapoptotic kinase MST2 coordinates signaling crosstalk between RASSF1A, Raf-1, and Akt. Cancer Res 70 1195-1203, 2010.

194. Kim D, Shu S, Coppola MD, Kaneko S, Yuan ZQ and Cheng JQ: Regulation of proapoptotic mammalian ste20-like kinase MST2 by the IGF1-Akt pathway. PLoS One 5: e9616, 2010. 